\title{
Methodology of curriculum development
}

\author{
Nathalie Tabin ${ }^{1}$, Carine Pannetier ${ }^{1}$, Daiana Stolz ${ }^{2}$ \\ ${ }^{1}$ Education Department, European Respiratory Society, Lausanne, Switzerland; ${ }^{2}$ Clinic of Respiratory Medicine and Pulmonary Cell Research, \\ University Hospital Basel, Basel, Switzerland \\ Correspondence to: Nathalie Tabin. Education Department, European Respiratory Society, Av. Ste-Luce 4, 1003 Lausanne, Switzerland. \\ Email: Nathalie.tabin@ersnet.org.
}

Submitted Nov 12, 2018. Accepted for publication Jan 16, 2019.

doi: $10.21037 /$ jtd.2019.01.89

View this article at: http://dx.doi.org/10.21037/jtd.2019.01.89

The European Respiratory Society (ERS) aims to achieve standardisation of training across Europe, quality control for all aspects of training, free movement of trainees across centres and nations and the delivery of the best care to patients with respiratory diseases.

The ERS methodology, aligned closely to the Kern et al. framework (1), involves the following steps which will be outlined in this article:

(I) Training needs assessment;

(II) Situation analysis;

(III) Curriculum development;

* Topic selection (syllabus);

* Development of learning outcomes (curriculum).

(IV) Implementation (both through teaching and learning opportunities and assessment);

(V) Evaluation and review.

\section{Assessment of the training need}

Assessment of the training need, i.e., "needs assessment" focuses on the "desired results" or on the "gap" that exists in current performance/delivery. The projects come into place because of needs assessment, which explains why it is necessary to cover a certain topic and how the project will meet the educational need. The logic and rationale for the project is defined in terms of the "gap" or the "desired results". Once the Educational Council, an expert, focus group that decides on ERS educational priorities, has approved the project, a task force is established. The task force is comprised of stakeholders with different backgrounds.

\section{Situation analysis}

The first phase is to analyse the current situation: the how, what, where, of current training been offered. Situational analysis is focused on the local situation within different countries; and it focuses on the activities required to affect the local situation. It evaluates the performance of activities and proposes a standard that can be applied to address the "gap". Based on this first step, the statement of intent is defined, outlining project objectives and scope including target audience and organisation of training.

\section{Curriculum development}

The first step is to define "what" to learn; a list of topics, the syllabus, and then to specify "how" to learn and teach those topics, the curriculum. The Figure 1 shows the different curricula developed through ERS methodology.

\section{Syllabus-topic selection}

The Delphi technique consensus-based method is used to define the programme content. Delphi is a "group communication process" that focuses on gathering information from a panel of experts, aiming to reach a convergence of opinion regarding a particular issue or set of issues (2). The consensus rate is agreed upon before the first round and is usually $80 \%$, even though there isn't any agreed proportion in the literature.

In the ERS projects, a modified Delphi technique is used, comprising usually of three rounds. During Delphi rounds, every participant works through a questionnaire (online 


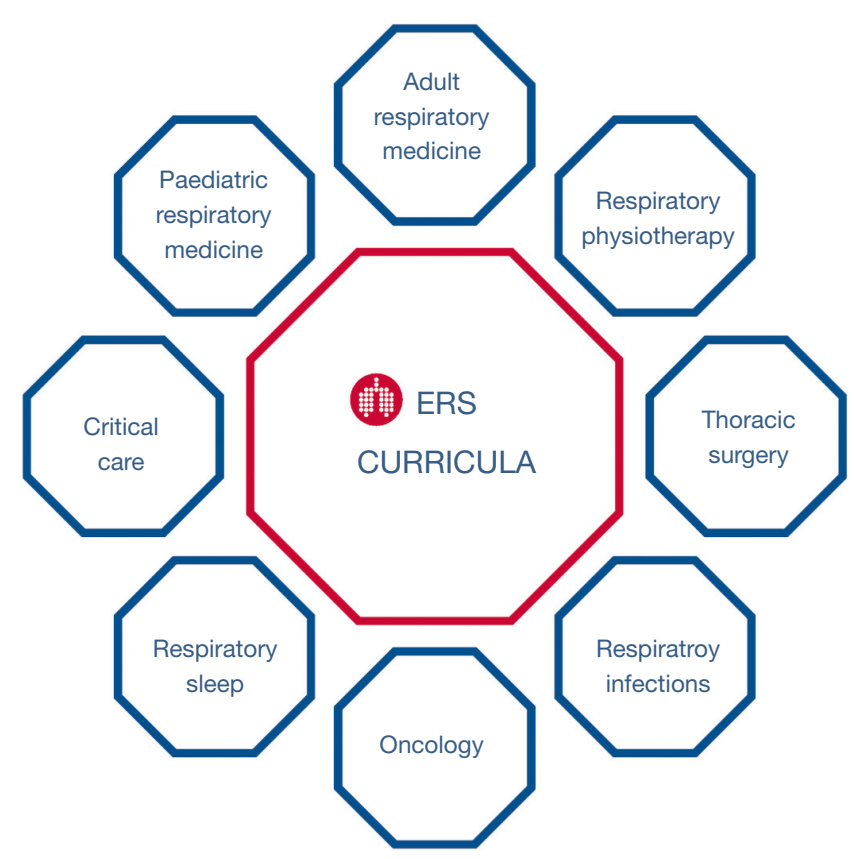

Figure 1 ERS curricula. ERS, European Respiratory Society.

survey tool: Survey Monkey) which is returned to the ERS Office; the results are collected, edited and presented to the task force members for more detailed discussions. For the second round, only the respondents of the first round are invited to participate. The Delphi rounds are phased in three different stages:

(I) A qualitative round involving all task force members is achieved through a facilitated focus group discussion face-to-face. A final review is done by the chair of the project for approving the syllabus draft before starting the survey;

(II) A semi-qualitative round with the task force members and chair of the project to approve the survey in the online environment;

(III) A quantitative round involving a large group of stakeholders including national experts in answering the online questionnaire. The data collection takes about six to seven weeks.

In Delphi studies, consensus is considered only a necessary (but not sufficient) condition for agreement concerning the inclusion of items. The iteration of rounds is required to establish the stability dimension of agreement.

\section{Curriculum}

Once the syllabus is defined, the curriculum matrix can be completed by the task force members. The curriculum expands on the syllabus content and specifies for each item:

* Learning outcomes that the target audience should acquire, which are divided into three domains: knowledge (cognitive skills), skills (psychomotor skills) and attitudes (affective skills). The "desired behaviour" must be written out using an active verb according to the bloom taxonomy (3). The conditions under which the behaviour must be done and the standards for successful completion of training must be stated as well. The CanMEDs framework is used as guide for writing the attitudes section (4);

* Level(s) of assessment based on Miller's model of clinical competence, which has to be assigned in alignment with the learning outcomes $(5,6)$;

* Assessment methods that are deemed fit for purpose which is essential to the validity of assessments and to predict whether a trainee is competent to practice; Different assessment instruments are used depending the level(s) of assessment defined and on overall goals of training, including online Multiple Choice Questions (MCQ), portfolio of performed procedures, objective structured clinical examination (OSCE), mini clinical evaluation exercise (MiniCEX) and direct observation assessment;

* Teaching and learning activities, which constitute work-based learning (participation in management of patients, or implementation of a treatment plan with patient collaboration), non-work-based learning (self-directed learning: formulation of own learning goals and identification of material resources for learning), formal learning (participate in a skillsbased course or attend meetings for formal training in specific areas), learning with other healthcare professionals (participation in interdisciplinary courses) and

* Minimum clinical exposure requirements (when relevant), such as the number of patient encounters considered necessary to practice without supervision.

\section{Implementation}

Planning and implementation of curricula involves the explicit organisation of each of the components within the curriculum and how they should come together (7). The design of the curriculum using a modular approach allow experts to follow different educational sessions to complete one full module using a blended learning approach. ERS 
has prioritized some modules in the curricula developed for implementation so far.

\section{Evaluation}

Any educational programme needs to be monitored and evaluated to ensure that delivery is taking place as planned and in line with the prescribed learning outcomes (8). The ERS curriculum design does not include an element for evaluation yet. Items or modules implemented by ERS through training programmes and courses includes elements of evaluation by participants.

\section{Conclusions}

Over the years, the process of curriculum design has been improved within ERS and it will continue to evolve. Our focus is the implementation and evaluation of evidencebased practice within medical education in all activities and developments. ERS strongly believes that a sound methodology and periodical revisiting of the curriculum development have a positive impact on the quality of postgraduate training and continuing medical education for respiratory physicians and allied health care professional across international borders.

\section{Acknowledgments}

Funding: None.

\section{Footnote}

Provenance and Peer Review: This article was commissioned by the Guest Editor (Gilbert Massard) for the series "Training in Pulmonary Medicine and Surgery" published in Fournal of Thoracic Disease. The article has undergone external peer review.

Conflicts of Interest: All authors have completed the ICMJE uniform disclosure form (available at http://dx.doi. org/10.21037/jtd.2019.01.89). The series "Training in Pulmonary Medicine and Surgery" was commissioned by the editorial office without any funding or sponsorship. NT reports being an Employee of ERS; CP reports being an Employee of ERS; DS reports payment form Astra-Zeneca AG, Novartis AG, GSK AG, Roche AG, Zambon, Pfizer and Schwabe Pharma AG, Vifor AG, outside the submitted work, and grants from Astra-Zeneca AG, Curetis AG,
Boston Scientific to the institution, outside the submitted work. The authors have no other conflicts of interest to declare.

Ethical Statement: The authors are accountable for all aspects of the work in ensuring that questions related to the accuracy or integrity of any part of the work are appropriately investigated and resolved.

Open Access Statement: This is an Open Access article distributed in accordance with the Creative Commons Attribution-NonCommercial-NoDerivs 4.0 International License (CC BY-NC-ND 4.0), which permits the noncommercial replication and distribution of the article with the strict proviso that no changes or edits are made and the original work is properly cited (including links to both the formal publication through the relevant DOI and the license). See: https://creativecommons.org/licenses/by-nc-nd/4.0/.

\section{References}

1. Kern DE. Curriculum development for medical education: a six-step approach. JHU Press, 1998.

2. Hsu CC, Sandford BA. The Delphi technique: making sense of consensus. Practical Assessment, Research \& Evaluation 2007;12:1-8.

3. Forehand, M. Bloom's taxonomy. In: Orey M. editor. Emerging Perspectives on Learning, Teaching, and Technology (E-Book). 2010:41-7. Available online: https://textbookequity.org/Textbooks/Orey_Emergin_ Perspectives_Learning.pdf

4. CanMEDS 2015. Available online: http://canmeds. royalcollege.ca/en/framework

5. Miller GE. The assessment of clinical skills/competence/ performance. Acad Med 1990;65:S63-7.

6. Zubair A., Seng CY, Khoo HE. Practical Guide to Medical Student Assessment. Hackensack, NJ: World Scientific, 2006.

7. Prideaux D. $\mathrm{ABC}$ of learning and teaching in medicine. Curriculum design. BMJ 2003;326:268-70.

8. McKimm J, Barrow M. Curriculum and course design. Br J Hosp Med (Lond) 2009;70:714-7.

Cite this article as: Tabin N, Pannetier C, Stolz D. Methodology of curriculum development. J Thorac Dis 2021;13(3):2035-2037. doi: 10.21037/jtd.2019.01.89 